\title{
Mothers' Satisfaction With Two Systems of Providing Care to Their Hospitalized Children
}

\author{
Masoumeh Hosseinian ${ }^{1}$; Neda Mirbagher Ajorpaz ${ }^{1, *}$; Soophia Esalat Manesh ${ }^{2}$ \\ ${ }_{1}^{1}$ Faculty of Nursing and Midwifery, Kashan University of Medical Sciences, Kashan, IR Iran

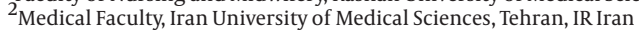 \\ ${ }^{*}$ Corresponding Author: Neda Mirbagher Ajorpaz, Faculty of Nursing and Midwifery, Kashan University of Medical Sciences, Kashan, IR Iran. Tel: +98-9131613899, Fax: +98-3615556633, \\ E-mail: mirbagher_n@kaums.ac.ir
}

Received: September 6, 2014; Revised: October 2, 2014; Accepted: October 20, 2014

\begin{abstract}
Background: Despite the paramount importance of the patient's satisfaction, there are limited data on mothers' satisfaction with the nursing care provided to their children in Iranian clinical settings.

Objectives: This study aimed to evaluate mothers' satisfaction with two systems of providing care to their hospitalized children.

Patientsand Methods:This research was a two-groupquasi-experimental study.Primarily, the basics of thecase method and the functional care delivery systems were educated to the practicing nurses of the study setting. Each system was implemented independently. After the implementation of each system, 200 mothers whose children were hospitalized in the pediatric care ward of Shahid Beheshti Hospital, Kashan, Iran, were invited to respond to the 28 -item Pediatric Family Satisfaction Questionnaire. Study data were analyzed by SPSS v. 16.0 . Results: Results were indicative of mothers' satisfaction with medical care delivered by case method as $13.2 \pm 5.2$ and by functional method as $13.17 \pm 5.56$. Also, no significant difference was seen between two groups $(P=0.4)$. Mothers' satisfaction with nursing care delivered by case method was $17.7 \pm 4.43$ and by functional method was $13.33 \pm 5.69$ and there was a significant difference between two groups (P $=0.004$ ). Mothers' satisfaction with accommodations by case method was $16.78 \pm 4.07$ and by functional method was $17.9 \pm 6.67$ with a significant difference between two groups $(\mathrm{P}=0.06)$.

Conclusions: Improving the quality of care is associated with higher patient's satisfaction. Accordingly, developing and implementing programs for improving nurses' communication and clinical skills can improve both care quality and patient outcomes.
\end{abstract}

Keywords:Personal Satisfaction; Nursing Care; Hospitalized Children

\section{Background}

Evaluating patient's satisfaction is a prerequisite to healthcare quality improvement and health budget allocation (1-3). It provides valuable information about the quality of health care services (4) as well as patients' healthcare needs. Accordingly, it can help healthcare providers to effectively fulfill patients' needs, facilitate their recovery, and promote their well-being (5). Patient's satisfaction is defined as patients' attitude toward and judgment about the degree of fulfilling their preferences and expectations by healthcare providers (6-8). In other words, there will be no quality care without patient's satisfaction. Patients who are more satisfied with the provided care are more compliant to the treatment regimen.

Hospitalization of children is fairly stressful for both children and their parents. Factors such as unknown prognosis of the underlying disease(s), repeated hospitalizations, need for receiving specialized healthcare services, and witnessing children's pain and fear would increase family members' stress and negatively affect their functions (9). Given the children's poor decision making ability, parents are usually involved in making decisions about the courses and types of treatments for their children. In other words, besides hospitalized children, their parents are considered as healthcare clients. As a result, parents' views can reflect their children's views (8). Previous studies reported that patients' level of satisfaction with healthcare services ranges from $47.1 \%$ to $96.7 \%$ (10, 11). Pourmovahed et al. investigated mothers' satisfaction with pediatric care in a local hospital in Iran. They found that $85.5 \%$ of the participating mothers evaluated medical services, nursing care, and accommodations as good or fairly good (3). Moreover, Hosseinian et al. found a direct relationship between mothers' satisfaction with healthcare services and the type of children's underlying conditions (12). Despite the paramount importance of patient's satisfaction, evaluating the quality of healthcare services from patients' perspectives has been neglected (13). Moreover, to the best of our knowledge, there are few studies on parents' satisfaction with nursing care that is provided in Iranian clinical settings. Therefore, this study was conducted for bridging this gap. 


\section{Objectives}

This study aimed to evaluate mothers' satisfaction with two systems of providing care to their hospitalized children.

\section{Patients and Methods}

This was a two-group quasi-experimental study. The study population consisted of all mothers whose children were hospitalized in the pediatric care ward of Shahid Beheshti Hospital, Kashan, Iran, for at least three days. Shahid Beheshti Hospital, Kashan, Iran is a general hospital with 500 beds and 22 wards. Pediatric ward has 33 beds and 22 nurses. The inclusion criteria were having Persian literacy and Iranian nationality. On the other hand, the exclusion criteria of the study were subjects' referring to other hospitals or death. The sample size was consisted of 200 participants in each group, using the formula for interventional studies. The study assumptions were as follows: the difference between the means of satisfaction of two groups is 24; the standard deviation is 12 ; the confidence of $95 \%$; and power of $80 \%$ (14). Sampling was performed in all working shifts throughout 2013 by using the convenience sampling method. We kept up sampling until reaching the predetermined sample size. The first, 200 samples were selected for case method care. After 3 months with changing in nursing care to functional method, 200 other samples selected for functional method by using the convenience sampling. Based on the inclusion and exclusion criteria, all samples remained in the study (Figure 1). A demographic questionnaire and the Pediatric Family Satisfaction questionnaire were used for data collection.

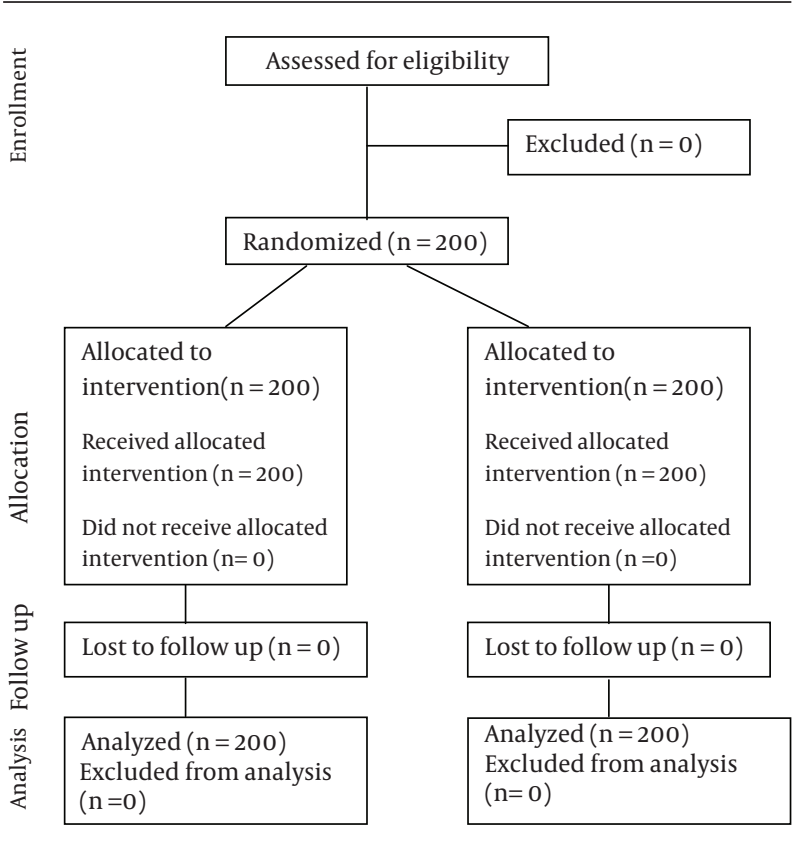

Figure 1. Sampling in This Study

\subsection{Questionnaire}

The demographic questionnaire consisted of questions regarding mothers' age, education, and the number of children as well as children's age, type of disease, and previous history of hospitalization. The 28 -item Pediatric Family Satisfaction Questionnaire (PFSQ) was used for evaluating mothers' satisfaction with healthcare services. PFSQ consists of three domains, including satisfaction with medical care ( 9 items), satisfaction with nursing care (11 items), and satisfaction with accommodations (8 items). Items are rated on a 5 -point Likert scale on which scores 1,2,3, 4, and 5 stand for poor, fairly poor, moderate, fairly good, and good, respectively. Accordingly, the possible total score of the questionnaire ranges from 28 to 140 . The validity and reliability of PFSQ were assessed and confirmed in previous studies (14). Given the limited use of the questionnaire in our country, we invited a panel of 10 faculty members affiliated to Kashan Faculty of Nursing and Midwifery, Kashan, Iran, to assess its content validity. The reliability of PFSQ was also evaluated by using the test-retest method. The time interval between the test and the retest measurements was 10 days. The test-retest correlation coefficient was 0.92. Ahmadiye et al. (15) also reported a Cronbach $\alpha$ of 0.78 for the questionnaire. Study data were collected at the time of hospital discharge by using the self-report technique.

\subsection{Procedure}

Our primary assessment of the study setting revealed that the dominant nursing system of care delivery in the setting was the case method system. Nonetheless, we provided the necessary education to the practicing nurses to ensure that all of them provide care by using a unified case method nursing system. In this system, each nurse takes responsibility for and coordinates the overall care of the allocated patient(s) (16). Then, 200 mothers whose children had received care by using the case method system were asked to complete the study instrument immediately before being discharged from hospital.

Thereafter, we trained the practicing nurses of the study setting to provide care by using the functional nursing system. The accurate implementation of the functional system was observed and confirmed too. In the functional nursing system, a certain task is assigned to each nurse; for instance, one nurse undertakes the task of drug administration while another one performs the dressing procedure (16). Then, 200 mothers whose children were cared for by using the functional method were asked to respond to the study instrument before hospital discharge. Sampling and data collection were performed by 3 research assistants blinded to the study intervention. Data collection for the case method and the functional systems lasted for 3 and 4 months, respectively. 
Hosseinian M et al.

\begin{tabular}{|c|c|c|c|}
\hline \multirow[t]{2}{*}{ Variables } & \multicolumn{3}{|c|}{ Demographic Data } \\
\hline & $\operatorname{Median} \pm \mathrm{IQR}$ & Case Method & Functional Method \\
\hline Children's age, mon & $30 \pm 48$ & $46.3 \pm 6.40$ & $38.54 \pm 8.36$ \\
\hline Mothers' age, $y$ & $29 \pm 9$ & $30.21 \pm 6.14$ & $29.37 \pm 6.67$ \\
\hline \multicolumn{4}{|l|}{ Education degree } \\
\hline Secondary education & - & $105.02(52.51)$ & $102.82(51.41)$ \\
\hline Diploma & - & $95.7(47.85)$ & $97.1(48.55)$ \\
\hline Acute diseases & - & $136.4(68.2)$ & $138(69)$ \\
\hline \multicolumn{4}{|l|}{ Jobs } \\
\hline Unemployed & - & $180(90.1)$ & $176(88.2)$ \\
\hline Employed & - & $20(0.9)$ & $26(12.8)$ \\
\hline \multicolumn{4}{|l|}{ Rating children } \\
\hline First & - & $106(53.1)$ & $106(53.1)$ \\
\hline
\end{tabular}

${ }^{\mathrm{a}}$ Data are presented as No. (\%) Mean $\pm \mathrm{SD}$.

Table 2. Comparison of Mothers' Satisfaction With the Two Nursing Care Delivery Systems

\begin{tabular}{lccccc}
\hline \multirow{2}{*}{ Satisfaction Care } & \multicolumn{2}{c}{ Case Method } & \multicolumn{2}{c}{ Functional Method } & \multirow{2}{*}{ Test } \\
\cline { 2 - 4 } & Mean \pm SD & Median $\pm \mathbf{I Q R}$ & Mean $\pm \mathbf{S D}$ & Median $\pm \mathbf{I Q R}$ & \\
\hline Medical Care & $13.2 \pm 5.2$ & $1 \pm 0$ & $13.17 \pm 5.56$ & $1 \pm 0$ & 0.4 \\
Nursing Care & $17.7 \pm 4.43$ & $1 \pm 0$ & $13.33 \pm 5.69$ & $1 \pm 0$ & 0.004 \\
Accommodations & $16.78 \pm 4.07$ & $1 \pm 0$ & $17.9 \pm 6.67$ & $1 \pm 0$ & 0.06 \\
Satisfaction & $47.68 \pm 16.67$ & & $44.4 \pm 17.92$ & & 0.2 \\
\hline
\end{tabular}

\subsection{Data Analysis}

Data management and analysis were performed by using the SPSS v. 16.0. The normality of the data was analyzed using Kolmogorov-Smirnov test $(\mathrm{P} \geq 0.05)$. Also, Mann-Whitney U test was applied where the distribution of the data was not normal. Mean score and standard deviation were calculated. Chi-square was used to compare nominal variables between two groups.

\subsection{Ethical Considerations}

We explained the study purpose to the participants and ensured the confidentiality of their information. Participation in the study was voluntary. Moreover, we obtained the necessary permissions from the chief nursing manager of the hospital and the dean of the pediatric care ward. The Ethics Committee of Kashan University of Medical Sciences approved the study protocol (grant No: 8957).

\section{Results}

The mean and the standard deviation of the participating mothers and their children's age were 30.21 \pm 6.14 years and $46.3 \pm 6.40$ months in case method and $29.37 \pm$ 6.67 years and $38.54 \pm 8.36$ months in functional method, respectively. About $52.51 \%$ of the participating mothers had primary or secondary education and the remaining $47.85 \%$ held high-school diploma or university degree. Most of the mothers were unemployed (90.1\%) and had acute diseases (68.2\%), (Table 1$)$. The results of the independent-samples t test revealed that there was no significant difference between the case method and the functional nursing systems in terms of mothers' overall satisfaction $(\mathrm{P}$ value $=0.2)$, their satisfaction with medical care $(P$ value $=0.4)$, and their satisfaction with accommodations $($ P value $=0.06)$, (Table 1$)$. However, compared with the functional method, mothers had greater satisfaction with the nursing care services, which had been provided by the case method system $($ P value $=0.04)$, (Table 2$)$.

\section{Discussion}

This study evaluated mothers' satisfaction with two systems of providing care to their hospitalized children. Study findings revealed that mothers' overall satisfaction with the two nursing care delivery systems did not differ significantly. Hosseinian et al. (12) also found that only $26 \%$ of mothers were satisfied with nursing care that was provided by the case method nursing system. Ladha et al. also reported medical and nursing care as the two main indicators of the patient's satisfaction. Studies have shown that patients who witness nurses' caring behaviors have higher satisfaction with care issue (4). Joolaee 
et al. also found that parents' needs during their children's hospitalization were significantly correlated with their gender, education, as well as nationality, and their children's age and disease (17). We also found that there was no significant difference between the case method and the functional nursing systems in terms of mothers' satisfaction with accommodation (17). Hosseinian et al. conducted a study to evaluate mothers' satisfaction with the care, which was provided by using the case method system. They also found that $37.8 \%$ of mothers were completely dissatisfied with accommodation (12).

Schaffer et al. found that factors such as effective nursepatient communication, mutual respect, and the safety and the pleasance of hospital physical environment were significantly contributed to parents' satisfaction. They also reported no significant difference between the two nursing system in terms of parents' satisfaction with accommodations (18). Demir et al. also reported medical and nursing care, medical equipment, and hospital nutritional services as the main determinants of patient's satisfaction. Study findings demonstrated that mothers' satisfaction with the nursing care provided by the case method nursing system was significantly higher than the functional system (19). Humpich et al. also found that patients had more positive perceptions towards the case method nursing system. The probable cause of this finding may be the nurses' more intense concentration on patients' needs as well as their more effective communication with patients in the case method system (20). According to Tzeng et al. attentive nurses who incorporate human emotions and the art of nursing into their practice and spend more time with their patients play an important role in promoting patient satisfaction, enhancing patients' compliance with treatment regimens, and improving the social and the professional status of the nursing (21).

The positive correlation between nurses' caring behaviors and patient's satisfaction implies that nurses should integrate human emotions and nursing art into their clinical practice, spend more time with their patients, and pay careful attention to patients' problems and the social aspects of care (21). However, Ziviani et al. noted that other intraorganizational and extraorganizational factors may contribute to patients' satisfaction with nursing care (22). We also found that there was no significant difference between two nursing systems regarding mothers' satisfaction with medical care. Hall found that the most important factor contributing to patient's satisfaction was the attending physicians' personal and professional conduct. Bakker et al. also noted that patients' poor compliance with treatment regimens as well as their complaints against physicians are mostly related to poor patient-healthcare provider communications (23). Hosseinian et al. also found that the quality of predischarge patient educations is poor to moderate (12). Schaffer et al. noted that parents expect to receive information about their hospitalized children's diseases, the prognosis of their diseases, and the course and the effectiveness of treatments (18).

Study findings also showed that for enhancing the quality of care and promoting mothers' satisfaction, healthcare providers need to adopt a patient-centered approach to care, establish close relationship with mothers, assess and fulfill their educational needs, and provide them with comprehensive pre-discharge patient education. Great patient satisfaction reflects the suitability and the effectiveness of the provided care as well as the degree of healthcare providers' awareness of and responsiveness to patients' preferences, expectations and biopsychosocial needs. Pype et al. found that adopting the primary approach to care significantly improved patient's satisfaction (24). Chen noted that given the rapid changes in the conceptualization of health and also in the healthcare quality assurance criteria as well as the healthcare clients' increased awareness of their rights, mother managers need to increase their motivation in caring childern (25). Such activities can promote mother's satisfaction, reduce their turnover, and enhance the quality of their care services (26).

The findings of the current study indicate that improving the quality of care can promote mothers' satisfaction with nursing care. Accordingly, developing and implementing programs for improving nurses' communication and clinical skills as well as adopting more effective approaches to care delivery can improve both care quality and patient outcomes.

\subsection{Study Limitations, Strengths, Weaknesses, and Recommendations}

The most important limitation of the study was as follows: 1) lack of cooperation and willingness of nurses, 2) inability to run two methods simultaneously.

Study strengths were cooperation of mothers and nursisand increased motivation in mothers and nurses. Weakness of the study was resistance of the nurses for changing in their care method. Replicating the same study in different clinical settings and investigating patients' and nurses' satisfaction with different nursing care delivery systems are recommended.

\section{Acknowledgements}

The research group would like to thank the Research Department of Kashan University of Medical Sciences for financial support of the project. We also appreciate the collaboration provided by mothers and nurses of Shahid Beheshti Hospital.

\section{Authors' Contributions}

Neda Mirbagher Ajorpaz contributed in design, data collection, statistical analysis and drafting of the manuscript. Masoumeh Hosseinian helped us in design and drafting of the manuscript. Sophia Esalat Manesh helped 
us in statistical analysis. Neda Mirbagher Ajorpaz supervised the study. All authors read and approved the final manuscript.

\section{Funding/Support}

This project was supported by Kashan University of Medical Sciences.

\section{References}

1. Malewski DF, Ream A, Gaither CA. Patient satisfaction with community pharmacy: comparing urban and suburban chain-pharmacy populations. Res Social Adm Pharm. 2015;11(1):121-8.

2. Ameryoun A, Pourtaghi G, Yahaghi E, Heidari S, Bahadori M, Ebrahimnia $\mathrm{M}$, et al. Outpatient and inpatient services satisfaction in Iranian military hospitals. Iran Red Crescent Med J.2013;15(9):843-7.

3. Pourmovahed Z, Dehghani K, Shakiba M, Shahri T. Mothers' satisfaction rate of hospital cares in the pediatric ward at sadoqi hospital of Yazd (2004). J Kermanshah Univ Med Sci. 2007;11(2):227-36.

4. Ladha K, Gupta R, Gill S, Verma M. Patient satisfaction with complete dentures fabricated using two neutral zone techniques: a within-subject cross-over pilot study. J Indian Prosthodont Soc. 2014;14(2):161-8.

5. Schoenfelder T, Schaal T, Klewer J, Kugler J. Patient satisfaction and willingness to return to the provider among women undergoing gynecological surgery. Arch Gynecol Obstet. 2014;290(4):683-90.

6. Torres EJ, Guo KL. Quality improvement techniques to improve patient satisfaction. Int J Health Care Qual Assur Inc Leadersh Health Serv. 2004;17(6):334-8.

7. Zineldin $\mathrm{M}$. The quality of health care and patient satisfaction: an exploratory investigation of the 5Qs model at some Egyptian and Jordanian medical clinics. Int J Health Care Qual Assur Inc Leadersh Health Serv. 2006;19(1):60-92.

8. Prieto-Diaz-Chavez E, Medina-Chavez JL, Brizuela-Araujo CA, Gonzalez-Jimenez MA, Mellin-Landa TE, Gomez-Garcia TS, et al. Patient satisfaction and quality of life following laparoscopic Nissen fundoplication. Rev Gastroenterol Mex. 2014;79(2):73-8.

9. Katz S. When the child's illness is life threatening: impact on the parents. Pediatr Nurs. 2002;28(5):453-63.

10. Otani K, Kurz RS, Burroughs TE, Waterman B. Reconsidering models of patient satisfaction and behavioral intentions. Health Care Manage Rev. 2003;28(1):7-20.

11. Kamimura A, Ashby J, Myers K, Nourian MM, Christensen N. Satisfaction with healthcare services among free clinic patients. $J$ Community Health. 2014;40:62-72.
12. Hosseinian M, Shahshahani MS, Adib-Hajbagheri M. Mothers satisfaction of hospital care in the pediatric ward of Kashan Shahid Beheshti hospital during 2010-11. Feyz J Kashan Univ Med Sci. 2011;15(2):153-60.

13. Green A, Davis S. Toward a predictive model of patient satisfaction with nurse practitioner care. J Am Assoc Nurse Pract. 2005;17(4):139-48.

14. Rajani S, Sawyer-Bennett J, Shirton L, DeHaan G, Kluthe C, Persad R, et al. Patient and parent satisfaction with a dietitianand nurse- led celiac disease clinic for children at the Stollery Children's Hospital, Edmonton, Alberta. Can J Gastroenterol. 2013;27(8):463-6.

15. Ahmadiye Yazdi M, Sharifi M. Pationt's satisfaction of hospital cares in hospitals of yazd Masters Thesis.: Tehran University Research; 2000.

16. Rose P, Yates P. Person centred nursing care in radiation oncology: A case study. Eur J Oncol Nurs. 2013;17(5):554-62.

17. Joolaee S, Haji Babaee F, Peyravi H, Haghani H. Nursing medication errors and its relationship with work condition in Iran University of Medical Sciences. Iran J Med Ethics Hist Med. 2010;3(1):65-76.

18. Schaffer P, Vaughn G, Kenner C, Donohue F, Longo A. Revision of a parent satisfaction survey based on the parent perspective. $J$ Pediatr Nurs. 2000;15(6):373-7.

19. Demir C, Celik Y. Determinants of patient satisfaction in a military teaching hospital. J Healthc Qual. 2002;24(2):30-4.

20. Humpich M, Byhahn C. [Invasive airway management update 2011]. Anasthesiol Intensivmed Notfallmed Schmerzther. 2011;46(9):608-16.

21. Tzeng HM, Ketefian S, Redman RW. Relationship of nurses' assessment of organizational culture, job satisfaction, and patient satisfaction with nursing care. Int J Nurs Stud. 2002;39(1):79-84.

22. Ziviani J, Darlington Y, Feeney R, Rodger S, Watter P. Early intervention services of children with physical disabilities: complexity of child and family needs. Aust Occup Ther J. 2014;61(2):67-75.

23. Bakker DA, Fitch MI, Gray R, Reed E, Bennett J. Patient-health care provider communication during chemotherapy treatment: the perspectives of women with breast cancer. Patient Educ Couns. 2001;43(1):61-71.

24. Pype P, Wens J, Stes A, Grypdonck M, Eynden BV, Deveugele M. Patients' nursing records revealing opportunities for interprofessional workplace learning in primary care: a chart review study. Educ Health (Abingdon). 2014;27(1):89-92.

25. Chen I, Hung CH. [Nursing motivation leadership]. Hu li za zhi J Nurs. 2007;54(1):83-9.

26. Corbett AM, Francis K, Chapman Y. Feminist-informed participatory action research: a methodology of choice for examining critical nursing issues. Int J Nurs Pract. 2007;13(2):81-8. 